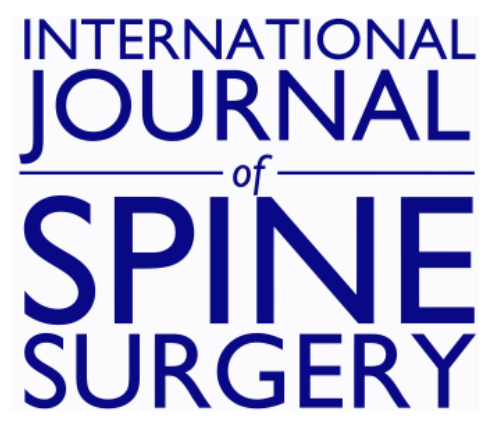

\title{
Tumor Occupancy Ratio-An Imaging Characteristic Prognosticating the Surgical Outcome of Benign Intradural Extramedullary Spinal Cord Tumors
}

Prashant Raj Singh, Tarun Kumar Pandey, Raghavendra Kumar Sharma, Faran Ahmad, Ankur Kumar and Abhay Agarwal

Int J Spine Surg 2021, 15 (3) 570-576

doi: https://doi.org/10.14444/8077

http://ijssurgery.com/content/15/3/570

This information is current as of April 26, 2023.

Email Alerts Receive free email-alerts when new articles cite this article. Sign up at: http://ijssurgery.com/alerts 


\title{
Tumor Occupancy Ratio-An Imaging Characteristic Prognosticating the Surgical Outcome of Benign Intradural Extramedullary Spinal Cord Tumors
}

\author{
PRASHANT RAJ SINGH, DNB,${ }^{1}$ TARUN KUMAR PANDEY, MS, MCH ${ }^{2}$ RAGHAVENDRA KUMAR \\ SHARMA, MS, MCH, ${ }^{1}$ FARAN AHMAD, DNB,${ }^{2}$ ANKUR KUMAR, DNB,${ }^{2}$ ABHAY AGARWAL, MS, DNB ${ }^{2}$ \\ ${ }^{1}$ Department of Neurosurgery, All India Institute of Medical Sciences, Raipur, India ${ }^{2}$ Department of Neurosurgery, Vivekananda Polyclinic and Institute of \\ Medical Sciences, Lucknow, India
}

\begin{abstract}
Background: Intradural extramedullary (IDEM) spinal cord tumors are two thirds of all spinal tumors. We have prospectively analyzed the importance of the tumor occupancy ratio as a factor for predicting the course of the disease and in prognosticating the surgical outcome in patients with IDEM tumors.

Methods: We prospectively analyzed 44 consecutive cases of IDEM tumors, diagnosed as cervical, thoracic, and lumbar IDEM tumors (excluding conus/cauda equina lesion) by magnetic resonance imaging (MRI), that were operated on at our institution between 2014 and 2016. We measured the tumor occupancy ratio and noted the sagittal and axial location of the tumor in the preoperative MRI and performed the laminectomy and unilateral medial facetectomy. A primary outcome has been noted according to the gait disability score in the preoperative period and in the follow-up period of 1 year. In the statistical analysis, categorical variables were compared using a chi-square test, and an analysis of variance and student $t$ tests were used for the continuous variables. $P<.05$ was considered statistically significant.

Results: The tumor occupancy ratio showed a significant association to the preoperative gait disability score $(P<$ $.001)$ and also predicted that the surgical outcome is much better in patients with tumors with a low tumor occupancy ratio than in patients with tumors with a high occupancy ratio $(P<.001)$. No difference in the tumor occupancy ratio was noted in 2 different pathological tumors, and there was also no difference in the tumor occupancy ratio at different sagittal and axial locations of the tumor.

Conclusion: Tumor occupancy ratio has shown a significant impact on the preoperative course and also predicts the surgical outcome in patients with IDEM tumors. Hence, it is an important imaging characteristic to prognosticate the outcome in IDEM tumors and should be noted in each case.
\end{abstract}

Tumor

\section{INTRODUCTION}

Intradural extramedullary (IDEM) spinal cord tumors constitute approximately two thirds of spinal tumors. ${ }^{1-3}$ The most common IDEM tumors are derived from nerve sheath cells covering the spinal nerve roots (schwannoma and neurofibroma) or meningeal cells located along the spinal cord surface (meningioma). ${ }^{3}$ The natural history of both of the common IDEM tumors were studied, and it was suggested that schwannoma has a varied growth pattern while meningioma has a constant growth pattern. ${ }^{4}$

Both common IDEM tumors (schwannoma and meningioma) have specific imaging features of different $\mathrm{T} 1$ and $\mathrm{T} 2$ intensity along with the homogeneous or heterogeneous contrast enhancement, but dural tail and extradural extension differentiate both of them, and one author also suggested that the longitudinal diameter of the schwannoma is higher than of the meningioma in IDEM tumors. ${ }^{5,6}$ None of the studies have evaluated any radiological parameters other than location to establish their role in prognosticating the surgical outcome. Hence, in this paper, we present our single institution's surgical experience to prospectively analyze the effect of tumor occupancy ratio on the surgical outcomes of patients with IDEM tumors at 1-year follow-up.

\section{MATERIAL AND METHODS}

\section{Patient Selection}

A prospective study was performed for 2 years between June 2014 and June 2016 of all consecutive 44 patients operated on for IDEM tumors at our 

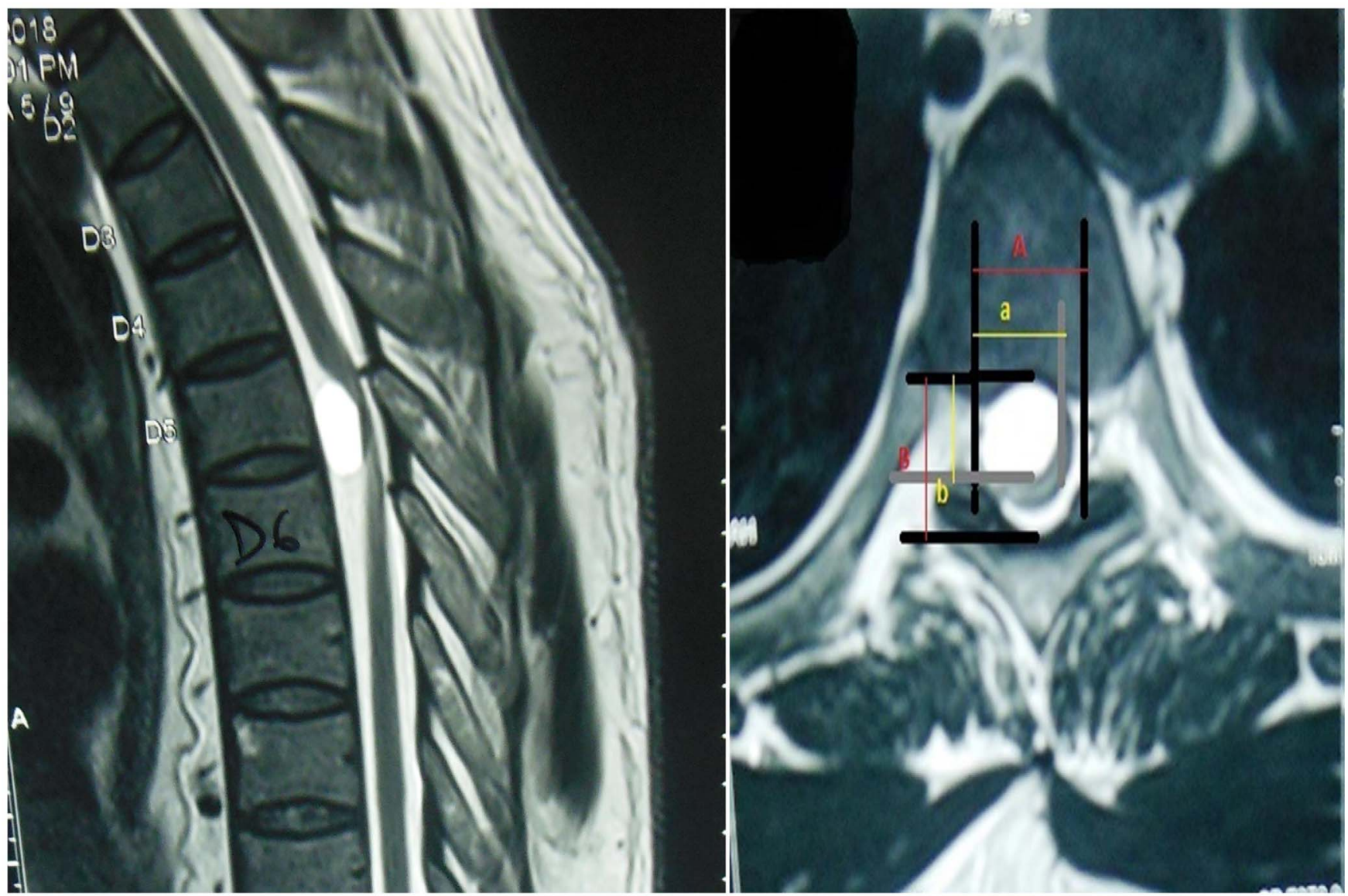

Figure 1. Magnetic resonance imaging (MRI; dorsal spine) of a ventrally located dorsal tumor showing the method of measurement of tumor occupancy ratio on an axial T2-weighted MRI image.

tertiary center. IDEM tumors at cervical, thoracic, and lumbar locations were selected except tumors at the cauda equina/conus locations. Ethical clearance was received from the ethical society of the institute, and written consent was received from all patients taking part in the study. A detailed clinical history was taken followed by careful clinical examination, which was recorded as per the written proforma.

\section{Preoperative Evaluation}

Diagnostic evaluations included magnetic resonance imaging (MRI) (spine) with contrast demonstrating the tumor and the respective spinal column (sagittal and axial) location of the lesion. The axial location of the tumor was categorized as anterior, posterior, or lateral with respect to the spinal cord and was described to correlate with a clock face. Tumor position according to the clock was divided into anterior with 10 o'clock and 2 o'clock positions, while 4 o'clock to 8 'o clock was defined as posterior, and the rest were considered as lateral.
The tumor occupancy ratio was also measured in axial MRI (spine) as described by $\mathrm{Ahn}$ et $\mathrm{al}^{7}$ and was done by the surgical team.

The tumor occupying ratio was measured as $[(\mathrm{a}+$ b) $/(\mathrm{A}+\mathrm{B})] \times 100$, where a is the transverse diameter of the tumor; $\mathrm{b}$ is the longitudinal diameter of the tumor; $\mathrm{A}$ is the transverse diameter of the intradural space; and $\mathrm{B}$ is the longitudinal diameter of the intradural space (Figure 1).

Clinical disability was assessed by the gait disability scale and Frankel scale at preoperation, time of discharge, 3 months, and 12 months followup by meeting or telephone. We have used a newer disability score system named the gait disability score, which mainly describes the ambulatory status of the patient. The gait disability score is a simplified version of the Frankel score and may be very useful and easy for mentioning and monitoring the ambulatory status of the patient. The following are the specifications of the gait disability score: 1 , nonambulatory; 2, ambulate with 2-men support/ walker; 3, ambulate with moderate assistance/1-man 
Table 1. Characteristics of the study population.

\begin{tabular}{lc}
\hline Characteristics & $\boldsymbol{n}(\mathbf{\%}), \boldsymbol{N}=\mathbf{4 4}$ \\
\hline Sex & \\
Male & $30(70.45)$ \\
Female & $14(29.55)$ \\
Age & \\
Less than 50 y & $30(68.18)$ \\
More than 50 y & $14(31.82)$ \\
Duration of illness & \\
Less than 6 mo & $17(38.64)$ \\
More than 6 mo & $27(61.36)$ \\
Tumor pathology & \\
Schwannoma & $28(63.64)$ \\
Meningioma & $16(36.36)$ \\
Tumor location (sagittal) & \\
Cervical & $9(20.45)$ \\
Upper thoracic & $12(27.27)$ \\
Lower thoracic & $16(36.36)$ \\
Lumbar & $7(15.90)$ \\
Tumor location (axial) & \\
Purely ventral & $6(13.82)$ \\
Purely dorsal & $3(6.81)$ \\
Lateral & $35(79.55)$ \\
Tumor occupancy ratio & \\
$\quad<80$ & $21(47.72)$ \\
$>80$ & $23(52.28)$ \\
Neurological status before surgery (gait disability & score) \\
Ambulatory & $26(59.09)$ \\
Nonambulatory & $18(40.91)$ \\
Neurological status at follow-up (1 year; gait disability score) \\
Ambulatory & $36(81.12)$ \\
Nonambulatory & $8(18.18)$ \\
\hline &
\end{tabular}

support; 4, ambulate with minimal assistance/stick support; and 5, ambulate without support.

\section{Surgical Intervention}

The preferred surgical procedure used in all cases was standard wide posterior laminectomies, while unilateral medial facetectomy was done in purely ventrally located tumors and in tumors with extradural extensions. The involved nerve rootlets with no distal end were identified and coagulated and cut in case of neurofibroma/schwannoma, while in the case of meningioma, dural origin was coagulated and cut if feasible using bipolar cauterization in most cases (Simpson grade II excision). Gross-total/near-total excision of the tumor was done in all cases. No implant fixation was done in any case. Intraoperative neuromonitoring was done in almost every case as a routine procedure.

\section{Follow-Up}

Postoperation, complications were immediately noted, and neurological status was again assessed at the time of discharge by the gait disability score and Frankel score, and the patient was then followed-up in the next 3 months and at 1 year. Postoperation radiology was only done in cases (2) with any deterioration in neurological status.

\section{Statistical Analysis}

Statistical analysis was carried out using statistical packages for SPSS 16.0 for Windows (SPSS Inc., Chicago, Illinois). Continuous and categorical variables were expressed as mean \pm standard deviation and percentages, respectively. Chi-square tests were done to determine the association between preoperative gait score and tumor occupancy ratio. A repeated measures analysis of variance was used to see the variations in gait disability score over time with different tumor occupancy ratios $(<80$ and $>80)$. An analysis of variance was applied to compare mean tumor occupancy ratios in lateral, ventral, and dorsal areas of axial sections and cervical, upper dorsal, lower dorsal, and lumbar locations of sagittal sections. An independent $t$ test was applied to compare the mean tumor occupancy ratio in schwannoma and meningioma. A value of $P<.05$ was considered statistically significant.

\section{RESULTS}

In this study, the age of all patients ranged from 16 to 75 years with a mean (standard deviation) of 42.6 (17.25) years. The patient population was $70.45 \%$ male, while only about one third $(29.55 \%)$ were female. In the sagittal location of the tumor, involved spinal levels were thoracic (63.65\%) followed by cervical $(20.45 \%)$ and lumbar $(15.90 \%)$ spine. In the axial location, tumors were distributed less in dorsal $(6.82 \%)$ and ventral $(13.64 \%)$, while the lateral $(79.55 \%)$ location was the most common. Out of 44 patients, $28(63.6 \%)$ had schwannoma, while $16(36.63 \%)$ patients had meningioma. Demographic, pathological types, and the final outcome of the study population are shown in Table 1. No significant difference was found in the mean tumor occupancy ratio measured at different sagittal $(P=.19)$ and axial locations $(P=$ $.92)$, and there was also no significant difference $(P$ $=.72$ ) in mean tumor occupancy ratio in both tumor types (schwannoma and meningioma) (Table 2).

The tumor occupancy ratio is associated with the preoperative gait disability score, and our results showed that tumors with poor gait score (more disability) had a higher occupancy ratio, suggesting that it directly affects the disability of the patient 
Table 2. Comparison of tumor occupancy ratio at different locations and tumor types.

\begin{tabular}{lrlll}
\hline Location & $\boldsymbol{N}$ & Mean & SD & $\boldsymbol{P}$ Value \\
\hline Axial & & & & .19 \\
$\quad$ Lateral & 35 & 79.57 & 6.28 & \\
$\quad$ Dorsal & 3 & 80.66 & 3.05 & \\
$\quad$ Ventral & 6 & 84.50 & 5.61 & .92 (ANOVA) \\
Sagittal & & & & \\
$\quad$ Cervical & 11 & 81.3636 & 7.81374 & \\
$\quad$ Lower dorsal & 16 & 79.9375 & 5.39714 & \\
$\quad$ Upper dorsal & 9 & 80.6667 & 4.58258 & \\
$\quad$ Lumbar & 6 & 81.5000 & 7.50333 & \\
Tumor pathological type & & & & .724 (independent \\
$\quad$ Schwannoma & 28 & 80.57 & 6.91 & $t$ test) \\
$\quad$ Meningioma & 16 & 79.87 & 4.80 & \\
\hline
\end{tabular}

Abbreviations: ANOVA, analysis of variance; SD, standard deviation.

and also shows a direct correlation $(r=0.66, P<$ .001) (Table 3 and Figures 2 and 3). When we compared tumors with $<80$ and $>80$ tumor occupancy ratios, we elucidated that the mean gait disability score changed more in tumors with a $<80$ tumor occupancy ratio and finally have a better outcome on the disability score at 1 year $(P<.001)$ (Table 4 and Figure 4).

According to the gait disability score, on presentation, most of the patients were at grade 4 $(38.64 \%)$, followed by grade $2(25 \%)$, grade 5 $(18.18 \%)$, grade $1(15.91 \%)$, and grade $3(2.27 \%)$. There was deterioration in 2 cases (one in the purely ventral upper thoracic location, while the other was a ventrolateral high cervical tumor with extraforaminal extension) in the immediate postoperative period, and both had residual weakness at 1-year follow-up, indicating the role of location in predicting the outcome, although the number of ventral tumors is less predictive of significance. In the postoperative period, we have seen that within 7 days after surgery, approximately $60 \%$ of patients were walking, either with minimal support or independently (grade 4 and 5). At 12 months follow-up, $90.91 \%$ of patients had a gait disability score $>2$, showing significant improvement (Table 5 and Figure 5), while $81.82 \%$ were ambulatory and

Table 3. Association of mean tumor occupancy ratio with preoperative gait score.

\begin{tabular}{lrccc}
\hline $\begin{array}{l}\text { Preoperative Gait } \\
\text { Disability Score }\end{array}$ & $\boldsymbol{N}$ & Mean & SD & $\boldsymbol{P}$ Value \\
\hline Score 1 & 7 & 84.00 & 5.62 & $<.001$ (ANOVA) \\
Score 2 & 11 & 86.00 & 4.07 & \\
Score 3 & 1 & 80.00 &. & \\
Score 4 & 17 & 77.88 & 4.79 & \\
Score 5 & 8 & 74.50 & 3.74 & \\
\hline
\end{tabular}

Abbreviations: ANOVA, analysis of variance; SD, standard deviation.

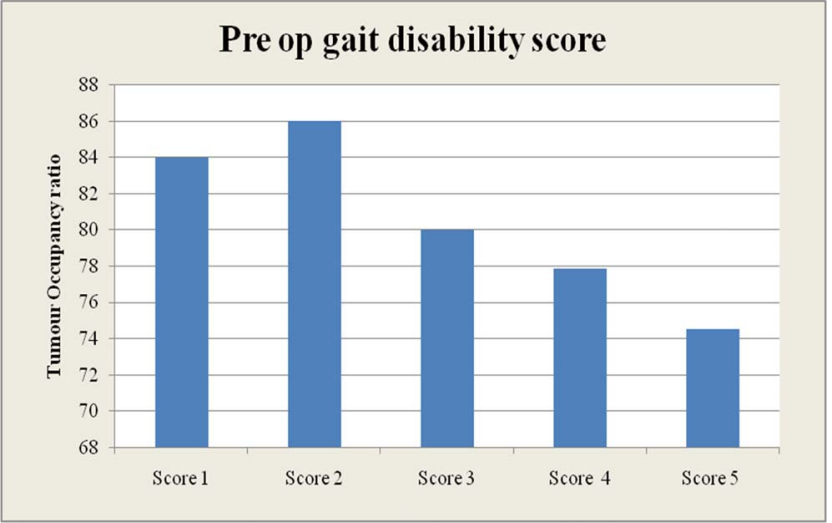

Figure 2. Bar diagram showing the relationship between tumor occupancy ratio and preoperative gait disability score.

$18.18 \%$ were nonambulatory as analyzed by the Frankel score (Table 6 and Figure 6).

No immediate complications of cerebral spinal fluid leak, hematoma, or wound infection was noted in our study.

\section{DISCUSSION}

Imaging characteristics of IDEM tumors is usually limited to T1, T2 intensity and contrast enhancing changes, and very few studies have also measured the longitudinal and transverse diameter of the tumors and tumor occupancy ratio; $;^{5-7}$ but none of the studies have ever tried to find the role of this feature in predicting the prognosis of surgical outcome in these patients. We have seen that tumor occupancy ratio not only correlated with preoperative disability of patients but also predicted the final outcome of these IDEM tumors. Patients with tumors with lower tumor occupancy ratios had low preoperative gait scores and recovered better than patients with tumors with high occupancy ratios, as

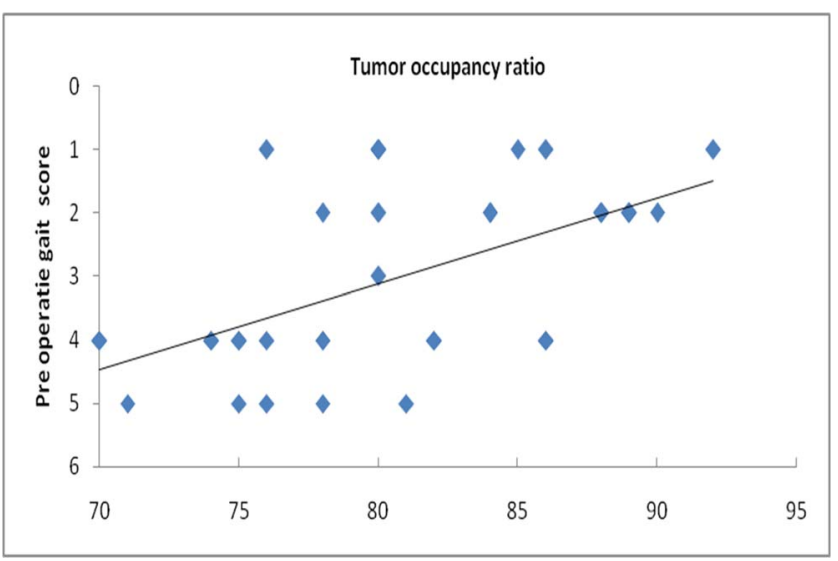

Figure 3. Linear correlation between tumor occupancy ratio and gait disability score. 
Table 4. Changes in gait disability score over time in different tumor occupancy ratios.

\begin{tabular}{lccccc}
\hline & \multicolumn{2}{c}{ Ratio $<\mathbf{8 0}$} & & \multicolumn{2}{c}{ Ratio $>\mathbf{8 0}$} \\
\cline { 2 - 3 } \cline { 5 - 6 } & Mean & SD & & Mean & SD \\
\hline Preoperative & 3.72 & 1.30 & & 2.47 & 1.26 \\
Discharge & 4.48 & 0.77 & & 3.26 & 0.93 \\
3 mo & 4.84 & 0.37 & & 4.15 & 0.89 \\
12 mo & 5.00 & 0.00 & & 4.68 & 0.58 \\
$P$ value & \multicolumn{2}{c}{$<.001$} & & $<.001$ (RM-ANOVA) \\
\hline
\end{tabular}

Abbreviations: RM-ANOVA, repeated measures analysis of variance; SD, standard deviation.

shown in the results. Hence, we can conclude that the tumor occupancy ratio should be used as a routine parameter in the preoperative evaluation of IDEM tumors and can help prognosticate the outcome in such tumors.

Few studies have also shown that tumor location has a significant impact on surgical outcome. ${ }^{1,6,8}$ In our case study, we have seen that ventrally located tumors trended toward the development of neurological deficit, as occurred in our 2 patients; but, because of the small number of ventral tumors in our study, it is not statistically significant. Two cases that have deterioration in our study have ventral location, one in the upper thoracic region and the other in the high cervical region with extradural extension. As we know, tumors located in the upper thoracic spine are more likely to develop postoperative neurological deficits because of anatomical limitations at these levels and insubstantial blood supply to that region. ${ }^{1,6,9}$ The extradural extension may also have a propensity to cause root/spinal cord-related neurological deficits, and the chances of recurrence are also high in such cases, while cervical spinal schwannoma with extradural extension has more of a chance of recurrence than at any other location. ${ }^{10-13}$

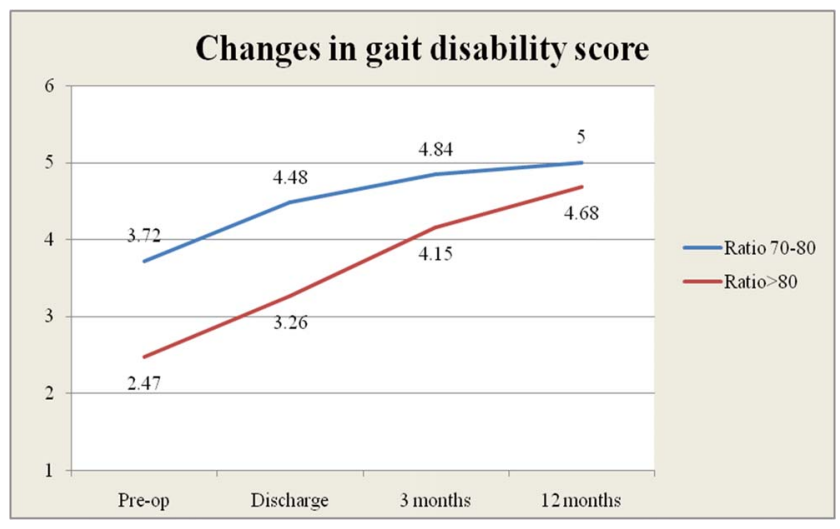

Figure 4. Correlation between preoperative and postoperative gait disability score at a different tumor occupancy ratio.
Table 5. Changes in gait disability score in preoperative and postoperative periods.

\begin{tabular}{lccr}
\hline & \multicolumn{2}{c}{ Gait Score, $\boldsymbol{n} \mathbf{( \% )}$} & \\
\cline { 2 - 3 } & $\leq \mathbf{2}$ & $\mathbf{> 2}$ & $\boldsymbol{P}$ Value \\
\hline $\begin{array}{l}\text { Preoperative period } \\
\text { Postoperative period } \\
\text { (at 12-mo follow-up) }\end{array}$ & $\begin{array}{c}18(40.91) \\
4(9.09)\end{array}$ & $26(59.09)$ & .0005 \\
\hline
\end{tabular}

The surgical approach is determined primarily depending on the location of tumors in the spinal canal, although the standard posterior approaches through bilateral or unilateral laminectomy with or without unilateral medical facetectomy provide adequate exposure to safely remove the vast majority of these lesions. ${ }^{8,14-16}$ Posterior fixation is not required in cases of unilateral facetectomy or part of rib removal, and we have not done it in any case even if we required multilevel laminectomy; but certain studies favored the minimally invasive approach in view of postoperative kyphosis. $6,12,17,18$

The majority $(90 \%)$ of clinical improvement was noted within 3 months of the operative intervention, while at 12 months of follow-up, there was significant improvement in both the gait disability score and Frankel score, as discussed in the results. As we know, complete surgical excision of IDEM tumors is possible with good preoperative planning according to the imaging characteristics and location after following the surgical principle. The complete excision of the tumor helps to prevent recurrence; hence, it is also a good predictor of clinical outcome and should be attempted. . $^{3,12,19-21}$

Spine centers have started, as a routine practice, to do neurophysiological monitoring in most cases of spinal surgery across the globe, but still have not proven its utmost importance in IDEM tumors. ${ }^{9,22}$

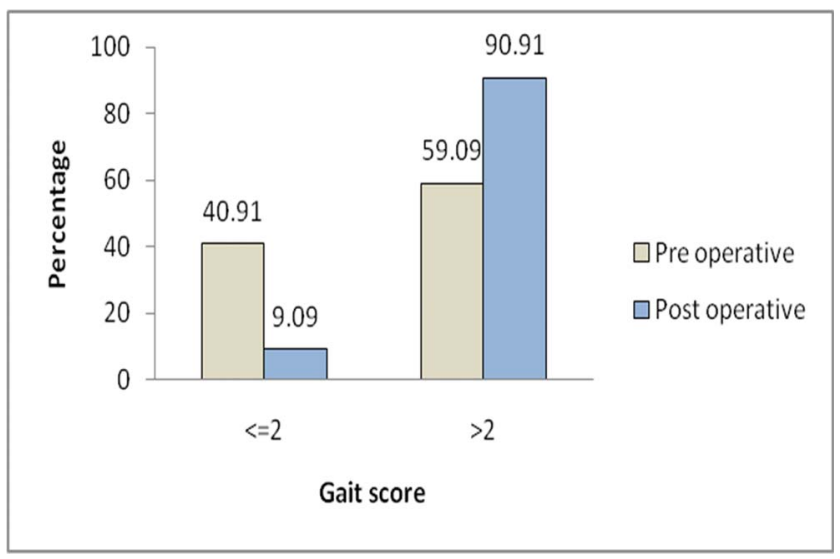

Figure 5. Changes in gait disability score in preoperative period and in followup at 12 months (significant is a $>2$ change in score). 
Table 6. Final outcome in the postoperative period based on Frankel score.

\begin{tabular}{|c|c|c|c|}
\hline & \multicolumn{2}{|c|}{ Frankel Score, $\boldsymbol{n}(\%)$} & \multirow[b]{2}{*}{$P$ Value } \\
\hline & Nonambulatory $(\mathrm{A}, \mathrm{B}, \mathrm{C})$ & Ambulatory (D, E) & \\
\hline $\begin{array}{l}\text { Preoperative ambulatory status } \\
\text { Postoperative ambulatory status (at 12-mo follow-up) }\end{array}$ & $\begin{array}{r}18(40.91) \\
8(18.18)\end{array}$ & $\begin{array}{l}26(59.09) \\
36(81.82)\end{array}$ & .019 \\
\hline
\end{tabular}

One benefit of intraoperative neuromonitoring is that it helps for intraoperative evaluation of nerve function and thus helps in excision of nonfunctional nerves. $^{22}$

Radiosurgery in intradural spinal tumors is evolving and seems to be an effective tool for patients who are not suitable for open surgery as well as with multiple lesions, recurrences, or tumor remnants after microsurgery. ${ }^{11,23}$

Our study has some limitations because of the smaller study population and the short follow-up period of only 1 year. Recurrence was also not commented on because of the unavailability of postoperative MRI in all patients and the limited duration of the study. The larger study sample size and randomization of the study may help in further validating the role of tumor occupancy ratios for predicting the surgical outcome of IDEM tumors.

\section{CONCLUSION}

MRI findings should be undertaken in a standardized fashion to ensure that important details are not missed for a more accurate evaluation of the location of the tumor. Tumor occupancy ratio should be measured routinely as it is correlated with the early clinical presentation of the patient and also predicts the surgical outcome and thus can be used as an important prognostic factor.

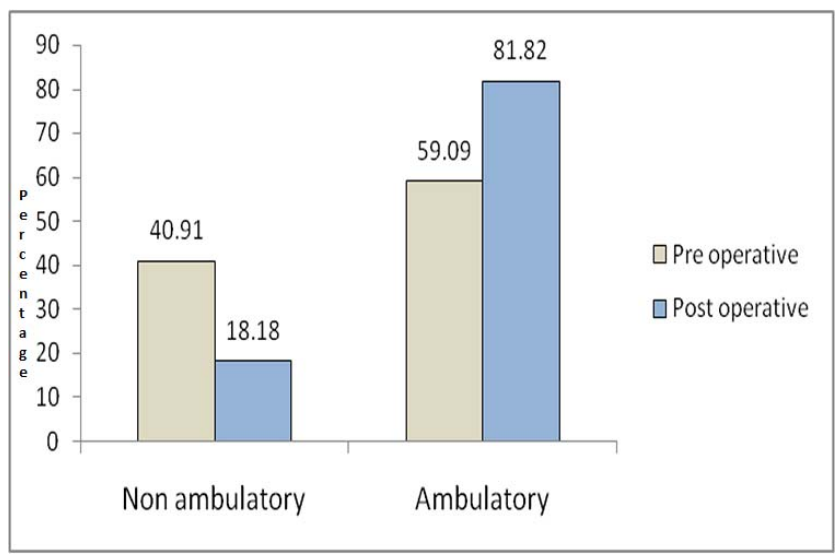

Figure 6. Final outcome of ambulatory status on the basis of Frankel score.
The location of the tumor was important to understanding the nature and course of the disease in these tumors. We have found deterioration in 2 ventrally located tumors; hence, we should be careful when operating on ventrally located tumors and also be cautious in cases of tumors with extradural extension.

\section{REFERENCES}

1. Mehta AI, Adogwa O, Karikari IO, et al. Anatomical location dictating major surgical complications for intradural extramedullary spinal tumors: a 10-year single-institutional experience. J Neurosurg Spine. 2013;19(6):701-707. doi:10.3171/ 2013.9.SPINE12913

2. Arora RK, Kumar R. Spinal tumors: trends from Northern India. Asian J Neurosurg. 2015;10(4):291-297. doi:10.4103/1793-5482.162707

3. Bhimani AD, Denyer S, Esfahani DR, Zakrzewski J, Aguilar TM, Mehta AI. Surgical complications in intradural extramedullary spinal sord tumors - an ACS-NSQIP analysis of spinal cord level and malignancy. World Neurosurg. 2018;117:e290-e299. doi:10.1016/j.wneu.2018.06.014

4. Ozawa H, Onoda Y, Aizawa T, Nakamura T, Koakutsu T, Itoi E. Natural history of intradural-extramedullary spinal cord tumors. Acta Neurol Belg. 2012;112(3):265-270. doi:10. 1007/s13760-012-0048-7

5. Liu J-B, Zhang Q, Liu G-Y, Zhu Q-S, Gu R. MRI diagnosis of intradural extramedullary tumors. $J$ Cancer Res Ther. 2014;10(4):927. doi:10.4103/0973-1482.137993

6. Tumialán LM, Theodore N, Narayanan M, Marciano FF, Nakaji P. Anatomic basis for minimally invasive resection of intradural extramedullary lesions in thoracic spine. World Neurosurg. 2018;109:e770-e777. doi:10.1016/j.wneu.2017.10. 078

7. Ahn D-K, Park H-S, Choi D-J, Kim K-S, Kim T-W, Park S-Y. The surgical treatment for spinal intradural extramedullary tumors. Clin Orthop Surg. 2009;1(3):165. doi:10.4055/cios. 2009.1.3.165

8. Slin'ko EI, Al-Qashqish II. Intradural ventral and ventrolateral tumors of the spinal cord: surgical treatment and results. Neurosurg Focus. 2004;17(1):1-8. doi:10.3171/foc. 2004.17.1.9

9. $\mathrm{Ng} \mathrm{Z}, \mathrm{Ng} \mathrm{S}, \mathrm{Nga} \mathrm{V}$, et al. Intradural spinal tumorsreview of postoperative outcomes comparing intramedullary and extramedullary tumors from a single institution's experience. World Neurosurg. 2018;109:e229-e232. doi:10.1016/j. wneu.2017.09.143

10. Emel E, Abdallah A, Sofuoglu OE, et al. Long-term surgical treatment outcomes of spinal schwannomas: retrospective analysis of 49 consecutively operated cases. Turk Neuro- 
surg. 2017;27(2):217-225. doi:10.5137/1019-5149.JTN.1567815.1

11. Fehlings MG, Nater A, Zamorano JJ, et al. Risk factors for recurrence of surgically treated conventional spinal schwannomas: analysis of 169 patients from a multicenter international database. Spine. 2016;41(5):390-398. doi:10.1097/BRS. 0000000000001232

12. Rinaldo L, McCutcheon BA, Kerezoudis $\mathrm{P}$, et al. Outcomes after surgical treatment of intradural-extramedullary spinal cord tumors: a review. WScJ. 2016;7(2):121-128.

13. Eroglu U, Bahadır B, Tomlinson SB, et al. Microsurgical management of ventral intradural-extramedullary cervical meningiomas: technical considerations and outcomes. World Neurosurg. 2020;135:e748-e753. doi:10.1016/j.wneu.2019.12. 145

14. Iacoangeli M, Gladi M, Di Rienzo, et al. Minimally invasive surgery for benign intradural extramedullary spinal meningiomas: experience of a single institution in a cohort of elderly patients and review of the literature. Clin Interv Aging. 2012;7:557-564. doi:10.2147/CIA.S38923

15. Raco A, Pesce A, Toccaceli G, Domenicucci M, Miscusi M, Delfini R. Factors leading to a poor functional outcome in spinal meningioma surgery: remarks on 173 cases. Neurosurgery. 2017;80(4):602-609. doi:10.1093/neuros/nyw092

16. Jenkinson MD, Simpson C, Miles J, Findlay GFG, Pigott TJD, Nicholas RS. Outcome predictors and complications in the management of intradural spinal tumors. Eur Spine J. 2006;15:203-210. doi:10.1007/s00586-005-0902-x

17. Sciubba DM, Chaichana KL, Woodworth GF, McGirt MJ, Gokaslan ZL, Jallo GI. Factors associated with cervical instability requiring fusion after cervical laminectomy for intradural tumor resection. J Neurosurg Spine. 2008;8(5):413419. doi: $10.3171 /$ SPI $/ 2008 / 8 / 5 / 413$

18. Zong S, Zeng G, Du L, Fang Y, Gao T, Zhao J. Treatment results in the different surgery of intradural extramedullary tumor of 122 cases. PLoS One. 2014;9(11):e111495. doi:10.1371/journal.pone.0111495

19. Angevine PD, Kellner C, Haque RM, McCormick PC.
Surgical management of ventral intradural spinal lesions. $J$ Neurosurg Spine. 2011;15(1):28-37. doi:10.3171/2011.3. SPINE1095

20. Song K-W, Shin S-I, Lee J-Y, Kim G-L, Hyun Y-S, Park D-Y. Surgical results of intradural extramedullary tumors. Clin Orthop Surg. 2009;1(2):74. doi:10.4055/cios.2009.1.2.74

21. Phan K, Vig KS, Ho YT, et al. Age is a risk factor for postoperative complications following excisional laminectomy for intradural extramedullary spinal tumors. Glob Spine J. 2019;9(2):126-132. doi:10.1177/2192568218754512

22. Harel R, Schleifer D, Appel S, Attia M, Cohen ZR, Knoller N. Spinal intradural extramedullary tumors: the value of intraoperative neurophysiologic monitoring on surgical outcome. Neurosurg Rev. 2017;40(4):613-619. doi:10.1007/ s10143-017-0815-2

23. Purvis TE, Goodwin CR, Lubelski D, Laufer I, Sciubba DM. Review of stereotactic radiosurgery for intradural spine tumors. CNS Oncol. 2017;6(2):131-138. doi:10.2217/cns-20160039

Disclosures and COI: None declared.

Corresponding Author: Dr Prashant Raj Singh, DNB, Assistant Professor, Neurosurgery, Department of Neurosurgery, All India Institute of Medical Sciences, Raipur, C.G, India. Phone: +91 (809) 040-5817; Email: prashantsingh2010@yahoo. com.

Published 1 June 2021

This manuscript is generously published free of charge by ISASS, the International Society for the Advancement of Spine Surgery. Copyright $\odot 2021$ ISASS. To see more or order reprints or permissions, see http://ijssurgery.com. 